\title{
Climate Study of the Learning Environment for Faculty, Staff, and Students at a U.S. Dental School: Foundation for Culture Change
}

\author{
C.A. Murdoch-Kinch, DDS, PhD; R.E. Duff, DDS, MS; V. Ramaswamy, PhD; \\ T.V. Ester, DDS; S.A. Sponseller, MSW, MUP; J.A. Seeley, PhD
}

Abstract: The aim of this study was to assess the culture and climate for diversity and inclusion and the humanistic learning environment for students, faculty, and staff at the University of Michigan School of Dentistry. From July 2014 to June 2015 , two committees of 16 faculty members, staff members, and students, in partnership with trained program evaluators, used a participatory program evaluation (PPE) process to conduct the assessment using key informant interviews, surveys, and focus groups. The topics addressed were humanistic environment, learning environment, diversity and inclusion, microaggressions and bullying, and activities and space. All staff members, all faculty members (both full- and part-time), and all students in all four years were invited to participate in the parallel but distinctive versions of the survey from November 10 to 25,2014 . Response rates for each group were as follows: 50\% (318/642) for students, 68\% (217/320) for staff, and 40\% (147/366) for faculty; numbers responding to individual items varied. Among the respondents, the majority ( $76 \%$ faculty, $67 \%$ staff, $80 \%$ students) agreed that the environment fostered learning and personal growth and that a humanistic environment was important (97\% faculty, 95\% staff, $94 \%$ students). Many reported having experienced/witnessed a micro-aggression or bullying. Many also reported having "ever had" dissatisfaction with the learning environment (44\% faculty, 39\% staff, $68 \%$ students). The students sought better relationships with the faculty; the staff and faculty members sought opportunities for professional development and mentoring. Recommendations included cultural sensitivity training, courses for interpersonal skills, leadership and team-building efforts, addressing microaggressions and bullying, creating opportunities for collaboration, and increasing diversity of faculty, staff, and students. These recommendations were incorporated into the school's strategic plan. In this study, a utilization-focused PPE process using mixed methods was effective for evaluating the dental school's climate for diversity and inclusion, as well as the learning environment for faculty, staff, and students.

Dr. Murdoch-Kinch is Clinical Professor, Department of Oral and Maxillofacial Surgery and Hospital Dentistry, and Associate Dean for Academic Affairs, University of Michigan School of Dentistry; Dr. Duff is Clinical Associate Professor, Department of Biological and Materials Sciences and Prosthodontics, and Assistant Dean for Student Services, University of Michigan School of Dentistry; Dr. Ramaswamy is Associate Director of Curriculum and Program Evaluation, University of Michigan School of Dentistry; Dr. Ester is Adjunct Clinical Associate Professor, Department of Cariology, Restorative Sciences, and Endodontics, and Director of Diversity and Inclusion, University of Michigan School of Dentistry; Ms. Sponseller is Associate Consultant, Learning for Action, San Francisco, CA; and Dr. Seeley is former Associate Director, Curtis Center Program Evaluation Group, University of Michigan School of Social Work. Direct correspondence to Dr. C.A. Murdoch-Kinch, School of Dentistry, University of Michigan, 1011 North University, Ann Arbor, MI 48109-1078; 734-763-5651; camurdoc@umich.edu.

Keywords: dental education, dental schools, humanistic culture, diversity, inclusion, climate, learning environment

Submitted for publication 3/31/17; accepted 4/23/17

doi: $10.21815 / J D E .017 .073$

$\mathrm{W}$ hen the Commission on Dental Accreditation (CODA) updated its standards for dental education programs in 2013 , the new standards elevated the emphasis on a dental school's climate and learning environment through several specific changes. Standard 1-3 states, "The dental education program must have a stated commitment to a humanistic culture and learning environment that is regularly evaluated." The intent state- ment explains that dental education programs should ensure collaboration, mutual respect, cooperation, and harmonious relationships among collaborators, faculty, students, staff, and alumni. Furthermore, Standard 1-4 states that "The dental school must have policies and practices to: ... c. Systematically evaluate comprehensive strategies to improve the institutional climate for diversity." The program is also expected to support and cultivate the development 
of professionalism and ethical behavior by fostering diversity of faculty, students, and staff, open communication, leadership, and scholarship. For Standard 1-4, "the dental school should develop strategies to address the dimensions of diversity including structure, curriculum, and the institutional climate and regularly evaluate that climate." These updated standards reflect the work of the American Dental Education Association Commission on Change and Innovation in Dental Education (ADEA CCI), as described by Haden et al. ${ }^{2}$

Research on the self-determination theory of human motivation has demonstrated that conditions that support an individual's experience of autonomy, competence, and relatedness foster enhanced engagement, performance, persistence, creativity, and learning. ${ }^{3,4}$ This theory defines the foundations for a humanistic learning environment for students, faculty, and staff and can be applied to the dental education context. Studies have also suggested that a humanistic environment is not only valued but has a positive impact on various outcomes. ${ }^{3,5}$ Furthermore, a humanistic environment should be explicitly supportive of diversity, equity, and inclusion.

The University of Michigan School of Dentistry (UMSD) has a long history and record of commitment to diversity and inclusion, starting in 1890 with the graduation of Dr. Ida Gray, the first African American woman to graduate from a dental school in the U.S. We have regularly evaluated our culture and climate, conducting two previous audits/studies at the UMSD: in 1995-96 and in 2009. Over the past 20-plus years, the results of these studies provided the basis for change initiatives to improve the climate and culture at the school, including establishment of the Multicultural Affairs Committee (MAC); conversion of the Office of Minority Affairs to the Office of Multicultural Affairs in 1991 and its evolution to the Office of Diversity and Inclusion in 2014; the establishment and implementation of health professions pipeline programs designed to increase the diversity of our student body; ${ }^{6,7}$ and the work of the MAC to provide programs and community events to support diversity and build an inclusive community at the school.

The aim of this study was to assess the culture and climate for diversity and inclusion and the humanistic learning environment for students, faculty, and staff at UMSD. This study built on the foundational data collected in the two previous cultural audits and expanded the scope of the assessment to explicitly include evaluation of the humanistic learning environment for students, faculty, and staff. Haden et al. described the ideal dental school environment as being characterized by two features. ${ }^{2}$ First, it encourages a humanistic approach that fosters respect, tolerance, understanding, and close professional relationships. Second, it promotes a learning environment that emphasizes provision of support services, focuses on learning rather than performance, and has an ethical climate and respect for individual learning styles. Both these features align with the basic principles of the humanistic approach of seeking relatedness to other human beings and self-actualization (the opportunity to grow and realize one's potential) and identify humanism as an important quality in a successful health care professional. ${ }^{8,9}$

\section{Methods}

The study was determined by the University of Michigan Health Sciences and Behavioral Sciences Institutional Review Board to be exempt from oversight (\#HUM00094243). In collaboration with consultants from the University of Michigan School of Social Work's Curtis Center for Program Evaluation (CCPEG), we used a mixed-methods, utilization-focused participatory program evaluation (PPE) process for the study. ${ }^{10}$ This approach involves the stakeholders as partners in program evaluation to ensure that the study will generate useful and relevant results. ${ }^{11,12}$ The evaluation team from CCPEG facilitated the year-long process and collaborated with UMSD students, faculty, and staff through the Climate Study Steering Committee (CSSC) and Climate Study Advisory Committee (CSAC). Data were collected using three methods: key informant interviews, a schoolwide survey, and focus groups. Each method included faculty (full- and part-time), student, and staff respondents. Patients were excluded from this study because their perspectives and experiences at the school were already being assessed via a Patient Services Survey.

In summer 2014, the CSSC and CSAC were formed to begin the study process. The CSSC guided the development of the larger CSAC, which included staff members, students, and faculty members from diverse backgrounds and demographic groups at the UMSD. Both committees played significant roles in developing the survey, interpreting key data, and preparing final recommendations. The CSSC consisted of the school's associate dean for academic 
affairs, assistant dean for student services, director of diversity and inclusion, and associate director for curriculum and program evaluation. They initiated the study process, obtained funding and support from the dean, and recruited the program evaluation team to work with the UMSD.

The CSSC members were also members of the CSAC. They worked with the program evaluation team from the CCPEG, meeting with them every other week, and were influential in guiding the direction of the study. This work included making decisions about the best use of the CSAC's limited time, carefully reviewing draft communications to be shared with the school community, and determining the timeline for the study. This group was also key in framing the context of the study within the UMSD, which informed important decisions such as when to launch the survey, how to communicate information with administrators, and how to define strategies for increasing credibility and buy-in.

The 16-member CSAC was created through consultation with stakeholders throughout the school. Support of each committee member's supervisor or department chair for the time commitment was obtained in advance. Participants committed to meeting with the evaluation team for one hour every week from August through April. Several early meetings were devoted to establishment of ground rules for our work together and discussion of definitions for a humanistic environment, diversity, inclusion, and learning environment. We also reviewed the two previous climate and cultural audits' results and the recommendations made and actions taken on the basis of that previous work. The committee agreed that it was essential to understand and acknowledge the experiences and information learned from these two prior studies prior to beginning this one. It was also imperative that the results lead to substantial and visible actions, communicated widely to our community.

The CSAC met weekly from July 2014 through March 2015. In the first few months, the CSAC was involved in developing a logic model, critiquing data collection methods, identifying key informants and pilot participants for the survey, and contributing to and reviewing draft survey questions. A logic model was created to provide a conceptual framework to guide development of the assessment tools: a webbased survey, key informant interview questions, and focus group scripts. The CSAC planned for the survey launch and established the project timeline. After the data were collected, its members interpreted survey and focus group data, planned the Town Hall meetings, and synthesized data to develop recommendations. The survey was piloted to test content validity and solicit feedback on the length. The final version was launched in November 2014, followed by focus groups held in January and February 2015. The schoolwide Town Halls occurred in April and May 2015.

\section{Key Informant Interviews}

To inform development of the schoolwide survey and increase the usefulness of its results to the school, the evaluation team conducted key informant interviews. The CSSC and evaluation team developed the interview protocols. The interviews included questions about the interviewees' past experience with climate surveys and their feelings about the UMSD's humanistic environment and overall experiences as a student, staff member, or faculty member. Interviewees were also asked for suggestions of new questions or topics they would like to see captured with the schoolwide survey.

The CSSC identified two staff members, two faculty members, one student, and one recent graduate as key informants. This group was selected based on a number of factors, such as active involvement in previous cultural audits and diversity of socioeconomic background, race/ethnicity, and life experience. Responses to the interview questions were categorized into four main themes: hierarchy issues, diversity and inclusion, learning environment, and lack of administrative support. The results of the key informant interviews helped in drafting questions for the survey.

\section{Schoolwide Surveys}

The program evaluation team and the CSAC collaborated to create a schoolwide survey using the two previous climate surveys in addition to themes from the key informant interviews. All questions were developed by the evaluation team and were reviewed and approved by the CSAC. The five main sections of the survey were humanistic environment, learning environment, diversity and inclusion, microaggressions and bullying, and activities and space. Each section had an introduction with definitions, followed by quantitative and qualitative questions. The final survey consisted of 43 questions in total, some of which had multiple parts. The survey is available from the corresponding author.

Humanistic environment. On the survey, we defined "humanistic environment" as follows: "The humanistic environment in the UMSD is one in which 
individuals promote respect, tolerance, understanding, and concern for all members, and community members continually work to create a supportive and inclusive environment. In the School of Dentistry's humanistic environment, students, staff, and faculty experience freedom from intimidation and judgment, close professional relationships, freedom to explore their environment, the opportunity to take appropriate risks within the environment, and the development of trusting and accepting relationships between members, regardless of institutional position or diversity of background."

The survey asked respondents to rate their level of agreement on a five-point Likert scale ( $1=$ strongly disagree to $5=$ strongly agree) for ten statements referring to a humanistic environment at UMSD. Statements addressed such issues as the importance of a humanistic environment, if the leadership was working towards fostering a humanistic environment, and if individuals at the school respect one another, are concerned for one another, and experience freedom from intimidation. Two open-ended questions asked in what ways the school did not meet the definition of a humanistic environment and in what ways the school could foster a humanistic environment. Up to three responses were solicited for each open-ended question.

Diversity and inclusion. Respondents rated their agreement on a five-point Likert scale ( $1=$ strongly disagree to $5=$ strongly agree) for statements about their belief that the school administration had an honest interest/concern for diversity, that most persons were satisfied with the state of diversity in the school, and the extent to which people at the school felt comfortable regardless of their gender, race/ethnicity, position in the school, socioeconomic status, etc. Two open-ended questions asked in what ways the staff, faculty, and students in the school are supported and in what ways these groups can be better supported. Up to three responses were solicited for each open-ended question.

Micro-aggressions and bullying. On the survey, we defined micro-aggressions as "brief exchanges, made intentionally or unintentionally, that invalidate or hurt a marginalized group" and said that bullying "may include verbal bullying (e.g., teasing, taunting), physical bullying (such as pushing and hitting), or intimidation." Participants were asked if they had experienced (observed and/or had been the victim of) micro-aggressions and bullying at the school and were asked to describe the incident if they had. Participants were also asked if they knew what actions to take if they had experienced (observed and/or been the victim of) any incident of microaggression or bullying.

Activities. Activities specific to each group (faculty, staff, students) were listed on the survey, and participants were asked if they had participated in the activity, were aware of the activity but did not participate, or were unaware of the activity and did not participate. All three groups were also asked to rate each activity on a three-point scale $(1=$ a great deal, $2=$ somewhat, $3=$ not at all) for the extent to which each promoted a humanistic environment. Activities for faculty and staff included meetings, appreciation banquets, retreats, schoolwide events (such as talent show and food bazaar), and informal activities (such as conversations in hallway and lunches in common spaces). Student activities included student organizations, orientation activities, schoolwide activities, and informal activities. Two open-ended questions asked what prevented participation in activities listed in this section and what additional activities the respondent would like to see offered. Up to three responses were solicited for each open-ended question.

Learning environment. The following working definition was provided on the survey: "The learning environment encompasses opportunities for staff, faculty, and students to experience professional growth and advancement." Participants were asked about the importance of various events or activities to the learning environment, if they ever felt dissatisfied with the learning environment, and, if the response was yes, to select the main areas of dissatisfaction. There were some common options and some that were specific for each group. Participants rated the extent to which they thought the various components of the learning environment were important to them on a five-point scale ( $1=$ not at all important to $5=$ very important) that also included a "not applicable" option. Some components were common, and some were specific to one group. For instance, a specific component for students was "required coursework," for staff was "staff meetings," and for faculty was "faculty meetings." Participants were also asked in what ways the learning environment at the school could be improved.

Demographics. These questions asked about the participants' age, gender, sexual orientation, religion, race/ethnicity, primary language, if they had to provide care for dependents, and number of years of experience at UMSD studying and/or working.

Three parallel but distinctive versions of the survey were administered in Qualtrics (Provo, UT, 
USA) to all staff members, all faculty members (both full- and part-time), and all students in all four years from November 10 to 25, 2014. The survey was accessed anonymously through a link on the school's secure intranet, MiTools. To increase response rates, members of the CSAC personally invited people in their classes or units; made announcements at faculty meetings, department meetings, and school leadership meetings; and posted announcements/reminders on the school's electronic message boards around the building, in addition to schoolwide emails and messages on the school's intranet.

\section{Focus Groups}

After the survey data were collected, the program evaluation team organized and presented the preliminary results to the CSAC, which then began the process of interpreting the objective data. The CCPEG evaluation team analyzed responses to the survey's open-ended questions for major themes and subthemes. The themes were quantified, and supporting illustrative quotes were chosen for the final report. Only a small percentage of respondents provided comments; therefore, themes from the qualitative comments were interpreted cautiously and were used in the final report primarily to identify areas for deeper exploration in the focus groups and as examples to illustrate potential areas for improvement.

The CSAC also identified several areas in need of more details. Focus group questions were designed by the CSAC and program evaluation team to gather this additional data in each of the six domains. Due to time constraints, none of the focus groups was able to discuss suggestions specific to activities. Themes from the activities section of the survey were presented in a stand-alone memo to the UMSD administrators.

\section{Results}

The survey response rates for each group were as follows: $50 \%(318 / 642)$ of students, $68 \%$ of staff (217/320), and $40 \%$ of faculty $(147 / 366)$. Numbers responding to individual items varied. Among the students, more than half identified themselves as Christian $(\mathrm{n}=167,57 \%)$, white $(\mathrm{n}=193,66 \%)$, and less than 30 years of age $(n=245,84 \%)$ (Table 1$)$. Among the staff members, more than half identified themselves as Christian ( $\mathrm{n}=116,59 \%)$, white $(\mathrm{n}=138$, $70 \%)$, and between 30 and 60 years of age $(n=152$, $77 \%$ ). Among the faculty members, more than half identified themselves as Christian $(\mathrm{n}=86,62 \%)$, white $(\mathrm{n}=83,61 \%)$, and between 30 and 60 years of age $(\mathrm{n}=78,58 \%)$.

\section{Humanistic Environment}

Overall satisfaction with their experience of a humanistic environment was higher for the responding faculty members and students than for the staff members on all items listed in Table 2. A majority of student, faculty, and staff respondents agreed/strongly agreed that individuals at the school experience an environment that facilitates learning and personal growth. Higher percentages of faculty and student respondents agreed/strongly agreed that individuals at the school experience a humanistic environment as compared to staff respondents. The lowest agreement was for staff respondents (46\%) on the statement that individuals at the school "experience freedom from intimidation." Also, only about

Table 1. Participants' demographic and professional characteristics, by number and percentage of respondents in each group (range: faculty=132-138, staff=194-198, students=290-296)

\begin{tabular}{|c|c|c|c|}
\hline Characteristic & Faculty & Staff & Students \\
\hline Male & $72(52 \%)$ & $37(19 \%)$ & $133(45 \%)$ \\
\hline Identify as gay or lesbian & $2(2 \%)$ & $6(3 \%)$ & $5(2 \%)$ \\
\hline Consider myself to have a disability & $7(5 \%)$ & $8(4 \%)$ & $5(2 \%)$ \\
\hline Christian & $86(62 \%)$ & $116(59 \%)$ & $167(57 \%)$ \\
\hline White & $83(61 \%)$ & $138(70 \%)$ & $193(66 \%)$ \\
\hline Primary language is English & $99(73 \%)$ & $176(89 \%)$ & $253(87 \%)$ \\
\hline Dependents to care for & $67(51 \%)$ & $95(49 \%)$ & $44(15 \%)$ \\
\hline \multicolumn{4}{|l|}{ Age } \\
\hline$<30$ years & $2(2 \%)$ & $15(8 \%)$ & $245(84 \%)$ \\
\hline 30 to 60 years & $78(58 \%)$ & $152(77 \%)$ & $42(14 \%)$ \\
\hline Years worked or studied at the school (0 to 15$)$ & $83(61 \%)$ & $150(76 \%)$ & $286(98 \%)$ \\
\hline
\end{tabular}


Table 2. Agreement with statements about humanistic environment at school, by number and percentage of respondents in each group (range: faculty $=141-147$, staff $=210-217$, students=314-318)

\begin{tabular}{|c|c|c|c|}
\hline Statement & Faculty & Staff & Students \\
\hline \multicolumn{4}{|l|}{ Individuals at the School of Dentistry: } \\
\hline experience a humanistic environment. & $106(72 \%)$ & $132(61 \%)$ & $228(72 \%)$ \\
\hline experience an environment that facilitates learning and personal growth. & $112(76 \%)$ & $145(67 \%)$ & $252(80 \%)$ \\
\hline respect one another. & $102(69 \%)$ & $135(63 \%)$ & $238(75 \%)$ \\
\hline are concerned for one another. & $91(62 \%)$ & $134(62 \%)$ & $207(66 \%)$ \\
\hline continually work to create a supportive environment. & $91(64 \%)$ & $124(59 \%)$ & $212(67 \%)$ \\
\hline continually work to create an inclusive environment. & $85(60 \%)$ & $108(51 \%)$ & $208(66 \%)$ \\
\hline experience freedom from intimidation. & $91(65 \%)$ & $98(46 \%)$ & $197(63 \%)$ \\
\hline $\begin{array}{l}\text { have the opportunity to develop trusting relationships with others, regardless of } \\
\text { their institutional position. }\end{array}$ & $90(63 \%)$ & $113(54 \%)$ & $226(72 \%)$ \\
\hline $\begin{array}{l}\text { It is important to me that the School of Dentistry community work toward creating } \\
\text { a humanistic environment. }\end{array}$ & $142(97 \%)$ & $207(95 \%)$ & $298(94 \%)$ \\
\hline The School of Dentistry leadership is committed to fostering a humanistic & $119(81 \%)$ & $152(70 \%)$ & $235(74 \%)$ \\
\hline
\end{tabular}
environment.

Note: Data represent both agree and strongly agree responses. Number of respondents varied for each item within the ranges shown.

$51 \%$ of staff respondents agreed/strongly agreed that individuals at the school "continually work to create an inclusive environment." These findings suggest that the staff members experience the environment differently from the faculty and students. However, a predominant majority in all three groups of respondents agreed/strongly agreed that it was important to them that the school work towards creating a humanistic environment. In comparison, the percentages who agreed/strongly agreed that the school leadership is committed to fostering a humanistic environment were slightly lower for all three groups.

In the qualitative responses to the question "How is the school currently not meeting the definition of a humanistic environment?," the most common themes in the comments from faculty and staff members were "unsupportive, individualistic environment" (14\%) and "lack of value and respect for staff" $(10 \%)$, respectively. For students, the most frequent themes were "intimidation and disrespect from faculty" (14\%) and "unsupportive, individualistic environment" (10\%). Table 3 illustrates four themes in responses to the question "In what ways, if any, could the School of Dentistry better foster a humanistic environment?"

\section{Learning Environment}

On the question "Have you ever felt dissatisfied with the learning environment as it relates to professional growth and advancement in the school?," $44 \%$ of faculty respondents, $39 \%$ of staff respondents, and
$68 \%$ of student respondents said yes. For faculty and staff respondents, the top area of dissatisfaction was opportunities for advancement. For student respondents, the top areas of dissatisfaction were curriculum requirements, interactions with faculty, and course requirements. On the question "In what ways, if any, could the learning environment at the School of Dentistry (including the above-listed activities) be improved to better support faculty professional development/staff professional development/student learning?," the major theme that emerged for staff respondents was professional development/training/ mentorship (21\%), including release time to attend activities; for faculty respondents, it was improving professional development/mentoring (55\%); and for student respondents, it was improving interactions with faculty $(35 \%)$.

\section{Diversity and Inclusion}

Respondents were also asked how comfortable they thought people at the school felt regardless of their gender, race or ethnicity, age, religious affiliation, socioeconomic status, sexual orientation, disabilities, family status, or position in the school. The responding students perceived individuals at the school were comfortable with respect to all the criteria listed (Table 4). However, for all three groups of respondents, the lowest agreement was for position in the school (faculty $58 \%$; staff $51 \%$; students $69 \%$ ). This finding suggests there are hierarchical issues in the culture. 
Although a large majority in all three groups agreed/strongly agreed that the school administrators had an honest interest/concern for diversity in the school (faculty $87 \%$; staff $76 \%$; students $74 \%$ ), a lower percentage agreed/strongly agreed that most persons were satisfied with the present state of diver-

Table 3. Four themes in responses to question "In what ways, if any, could the School of Dentistry better foster a humanistic environment?" with examples of comments

\begin{tabular}{|c|c|c|c|c|}
\hline Group & $\begin{array}{c}\text { Create a More } \\
\text { Supportive Environment }\end{array}$ & $\begin{array}{l}\text { Facilitate Intergroup } \\
\text { Interaction }\end{array}$ & $\begin{array}{c}\text { Tackle } \\
\text { Hierarchy Issues }\end{array}$ & $\begin{array}{l}\text { Tackle Intimidation } \\
\text { and Bullying }\end{array}$ \\
\hline Faculty & $\begin{array}{l}\text { Professional development } \\
\text { and advancement } \\
\text { Mentoring } \\
\text { Appreciation of individual } \\
\text { efforts } \\
\text { Foster open, collaborative } \\
\text { environment } \\
\text { Stress relief }\end{array}$ & $\begin{array}{l}\text { Physical space } \\
\text { Social activities } \\
\text { Cultural and diversity training } \\
\text { Promote interprofessional } \\
\text { collaboration }\end{array}$ & $\begin{array}{l}\text { Promote gender } \\
\text { equality } \\
\text { Diversify leadership }\end{array}$ & $\begin{array}{l}\text { Stricter consequences/ } \\
\text { no tolerance } \\
\text { Promote respect across } \\
\text { groups }\end{array}$ \\
\hline Staff & $\begin{array}{l}\text { Recognition } \\
\text { Training } \\
\text { Evaluations/feedback system } \\
\text { Interpersonal treatment } \\
\text { Better leadership } \\
\text { Accountability/consequences } \\
\text { Policy adherence }\end{array}$ & $\begin{array}{l}\text { More activities/events } \\
\text { Improve communication } \\
\text { University relations } \\
\text { Create staff area }\end{array}$ & $\begin{array}{l}\text { Eliminate favoritism } \\
\text { Eliminate hierarchy } \\
\text { Politics } \\
\text { Promote equality }\end{array}$ & \\
\hline Students & $\begin{array}{l}\text { Improve teaching } \\
\text { Curriculum changes } \\
\text { Student input/increasing } \\
\text { accountability } \\
\text { Balance and well-being }\end{array}$ & $\begin{array}{l}\text { Physical space } \\
\text { Increase intergroup } \\
\text { interaction }\end{array}$ & & $\begin{array}{l}\text { Faculty interactions with } \\
\text { students in front of patients } \\
\text { Training for faculty/improv- } \\
\text { ing faculty soft skills } \\
\text { Respect students' time }\end{array}$ \\
\hline
\end{tabular}

Note: Only the "Create a More Supportive Environment" category had more than $10 \%$ of respondents in all three groups that provided a comment.

Table 4. Respondents' agreement with statements about diversity and inclusion at the school, by number and percentage of respondents in each group (range: faculty=136-143, staff $=205-210$, students $=301-306$ )

\begin{tabular}{|c|c|c|c|}
\hline Statement & Faculty & Staff & Students \\
\hline \multicolumn{4}{|l|}{ It is easy for people to feel comfortable in this school regardless of their: } \\
\hline Gender & $116(82 \%)$ & $172(82 \%)$ & $259(85 \%)$ \\
\hline Race/ethnicity & $94(66 \%)$ & $147(70 \%)$ & $230(75 \%)$ \\
\hline Dis/abilities & $98(70 \%)$ & $141(67 \%)$ & $220(72 \%)$ \\
\hline Sexual orientation & $89(63 \%)$ & $146(70 \%)$ & $235(77 \%)$ \\
\hline Age & $106(75 \%)$ & $152(72 \%)$ & $259(85 \%)$ \\
\hline Religious affiliation & $107(79 \%)$ & $145(70 \%)$ & $245(81 \%)$ \\
\hline Family status (marital status, parenting status) & $110(80 \%)$ & $160(77 \%)$ & $259(86 \%)$ \\
\hline Educational background & $92(67 \%)$ & $129(63 \%)$ & $247(82 \%)$ \\
\hline Socioeconomic status & $97(71 \%)$ & $132(64 \%)$ & $226(75 \%)$ \\
\hline Position in the school & $79(58 \%)$ & $106(51 \%)$ & $209(69 \%)$ \\
\hline $\begin{array}{l}\text { I believe that the School of Dentistry administrators have an honest interest/concern } \\
\text { for diversity in the school. }\end{array}$ & $124(87 \%)$ & $160(76 \%)$ & $226(74 \%)$ \\
\hline $\begin{array}{l}\text { I believe that most persons (faculty, staff, students) are satisfied with the present state } \\
\text { of diversity in the School of Dentistry. }\end{array}$ & $84(59 \%)$ & $115(55 \%)$ & $195(64 \%)$ \\
\hline
\end{tabular}


sity in the school (faculty 59\%; staff 55\%; students 64\%) (Table 4). Events and organizations were reported by all three groups of respondents (faculty $73 \%$; staff $85 \%$; students $63 \%$ ) to be the main ways that staff members, students, and faculty members supported diversity and inclusion in the school community. The most frequent theme in responses from the staff for ways that staff members, students, and faculty members could be better supported and included in the school community was supporting professional development (12\%).

\section{Micro-Aggressions and Bullying}

Table 5 summarizes the percentage of responding faculty and staff members and students who reported ever having experienced or witnessed micro-aggressions and bullying at the school. More respondents in all three groups reported experiencing or witnessing micro-aggressions than bullying. A little over half of all three groups of respondents said they knew what actions to take if they witnessed an incident of micro-aggression and bullying. On the question "If you have experienced or witnessed micro-aggressions at the School of Dentistry, please describe the incident(s)," the most frequent response for students $(12 \%)$ was "Gender discrimination and stereotyping." On the question "If you have experienced or witnessed bullying at the School of Dentistry, please describe the incident(s)," the most frequent response for staff members $(10 \%)$ was "intimidation based on hierarchy."

After interpreting the survey data, the CSAC decided to present the recommendations and information from the activities and space section in a separate memo to the dean and the Multicultural Affairs Committee. The presentation included a recommendation for a coffee shop/cafeteria in the School of Dentistry to provide a space where the community could come together informally. The top five recommendations based on multiple sources of data from the study were as follows: implement cultural sensitivity training; provide internal courses for interpersonal skills, leadership, and team-building; create think tanks made up of students, faculty, and staff; create a clear, safe place to report incidents of micro-aggressions; and increase diversity of staff, faculty, and students.

\section{Discussion}

Our study is the first published study of the dental school environment that used a utilizationfocused, participatory program evaluation process. ${ }^{12}$ This process incorporated the various stakeholders into every step of the study to ensure that the findings would be valued and utilized, and it enabled integration of the findings and recommendations into the school's strategic plan with specific measurable actions.

Utilization-focused participatory program evaluation is a methodology whose primary function is to use evaluation for program, policy, or organizational decision making, as described by Suarez-Herrera and Kagan $^{12}$ and Cousins and Whitemore. ${ }^{13}$ The method is characterized by sustained interactivity between the evaluators and program stakeholders as partners, as well as increased stakeholder involvement in the evaluation, which was found by those investigators to increase responsiveness of the process to stakeholder needs and enhance utilization of the findings - two major goals for conducting a climate study in a dental education environment. It is important to note that this process was also found by Cousins and Whitemore to enhance utilization without compromising technical quality and to have positive effects on participants, including empowerment, appreciation, and acceptance of the evaluation and development of skills for systematic inquiry. ${ }^{13}$

In our study, the participants were the CSAC members and the constituencies each represented. One of the recommendations in the climate study

Table 5. Participants who responded "yes" to questions about incidents of micro-aggressions and bullying, by number and percentage of respondents in each group (range: faculty=137-142, staff=203-209, students=299-307)

\begin{tabular}{|c|c|c|c|}
\hline Question & Faculty & Staff & Students \\
\hline Have you experienced or witnessed micro-aggressions at the School of Dentistry? & $63(44 \%)$ & $66(32 \%)$ & $160(52 \%)$ \\
\hline Have you experienced or witnessed bullying at the School of Dentistry? & $42(30 \%)$ & $78(38 \%)$ & $65(21 \%)$ \\
\hline Do you know what actions you would take if you witnessed an incident of micro- & $83(61 \%)$ & $120(59 \%)$ & $165(55 \%)$ \\
\hline
\end{tabular}
aggression or bullying at the School of Dentistry?

Note: Number of respondents varied for each question within the ranges shown. 
report was to "create a think tank made up of faculty, staff, and students." In response to this recommendation, an implementation team comprised of faculty, staff, and students was formed. It represents an expanded membership of the MAC, a group already mandated to foster a climate supportive of diversity and inclusion. The new group, led by the director of diversity and inclusion, is leading implementation of the other recommendations of the study. Most of the CSAC volunteered to serve on this committee because of their positive experience in this process. We believe that their sense of ownership of the process also contributed to the high response rates in our survey.

As a result of the study, we identified six themes in the evaluation of our climate and learning environment. First, overall ratings of the dental school environment were satisfactory. A majority of responding students $(80 \%)$, faculty members $(70 \%)$, and staff members (67\%) agreed/strongly agreed that individuals at the school experience an environment that facilitates learning and personal growth (Table 2). Overall, all three groups perceived that people at the school were comfortable regardless of their gender, sexual orientation, race/ethnicity, age, religion, socioeconomic status, disabilities, or family status. The percentages that agreed/strongly agreed that the school leadership is committed to fostering a humanistic environment ranged from $70 \%$ to $81 \%$. Second, despite these results, a substantial number in all three groups reported witnessing/experiencing a micro-aggression incident and, to a lesser extent, a bullying incident (Table 5). A little over half of student respondents reported experienced a microaggression incident, and a little over a third of staff respondents reported witnessing a bullying incident.

Third, the faculty, staff, and student respondents indicated a need for a better learning environment. On the question "Have you ever felt dissatisfied with the learning environment, as it relates to professional growth and advancement in the school?," the percentages that said yes were $44 \%$ for faculty, $39 \%$ for staff, and $68 \%$ for students. Student respondents indicated a need for better relationships with faculty, seeing some faculty members as creating an intimidating atmosphere. Many studies have supported the importance of positive interactions between faculty and students to maintaining a humanistic climate $e^{14-16}$ and promoting academic performance for students. ${ }^{17,18}$ Faculty development can not only benefit faculty members, but also help create a learning environment that is conducive to encouraging learning. . $^{5,919-23}$
The need for faculty development has been stressed in many studies to improve faculty well-being and work-life as well as education innovation and student learning. ${ }^{4,5,9,20,22-24}$ Our study joins the recently published one conducted at the University of the Pacific in including the perceptions of dental school staff members in assessments, affirming that working in a humanistic environment is an important issue for them as well. ${ }^{25}$

Fourth, all three groups in our study indicated that it was not always easy for them to feel comfortable with others at the school regardless of their position. Staff respondents had the lowest satisfaction ratings in general as compared to faculty and student respondents on this issue. Themes that emerged in staff members' qualitative comments were intimidation based on hierarchy and lack of value and respect from faculty. Fifth, respondents indicated that endorsing a positive climate at the school needs to be backed by clear action. For instance, although a large majority ( $74 \%$ to $97 \%$ ) perceived the school administrators as having an interest in promoting diversity, a much lower percentage reported being satisfied with the state of diversity in the school $(55 \%$ to $64 \%$ ). As a result, one of the highest priority goals in our strategic plan is to increase the diversity of our students, faculty, and staff. Also, in all three groups of respondents, despite the common experience of witnessing a micro-aggression or bullying, only a little over half said they knew what actions to take.

Finally, a large majority of respondents in all three groups agreed/strongly agreed that it was important to them that the school work towards creating a humanistic environment (Table 2) and clearly valued positive interactions with others at the school. One way to promote positive interactions at the school may be through intergroup events and activities in which all persons can participate with minimal time constraints and scheduling concerns. Essentially, we have defined a humanistic climate as one in which there are good opportunities to learn and grow and there is relatedness. ${ }^{4}$

Since the completion of the study in June 2015, the UMSD has started to implement actions in direct response to recommendations by the study team through our schoolwide strategic planning process and in alignment with the university's Strategic Planning Initiative. These actions include the following: cultural sensitivity training workshops on "Unconscious Bias" for faculty (November 2016), staff (April 2017), and students (May 2017); "bystander training" workshops to prevent and address 
micro-aggressions and bullying integrated into firstyear orientation sessions (June 2015) and, starting in 2016, for students, staff, and faculty throughout the year; an increase in scholarship dollars, targeted fundraising, and expansion of our "Profiles for Success" health professions pipeline programs (these efforts have resulted in a threefold increase in the number of students entering the DDS program from underrepresented minority populations and disadvantaged backgrounds from 2015 to 2016); and a new Faculty Professional and Career Development Program to support ongoing faculty development in teaching and education for full-time and part-time faculty members, implemented in 2017. Finally, a cafe was opened in our building in February 2017. We will repeat the study in three to five years to evaluate how the recommendations have resulted in changes in how the environment is perceived by our community members.

A major limitation of this study is that the results are based on findings from a single school, so our conclusions and recommendations may not be generalizable to other dental schools. Replication in other settings will be needed to further validate the study findings and provide more insight into the learning environment across U.S. dental education. Another limitation is that patients, who are major stakeholders with a distinctive perspective on our environment, were not included in this study. In addition, many of the questions on the survey were new, so we were unable to compare the responses on those to the results of our previous cultural audits to evaluate change over time. Finally, the data were self-reported, which includes the possibility of bias, especially desirability bias for this type of survey, and some respondents skipped individual items, meaning the data were incomplete on those questions.

\section{Conclusion}

This is the first published account of a climate study of the learning environment for students, faculty, and staff at a dental school using a utilizationfocused participatory program evaluation approach. This process produced findings about our humanistic environment that are consistent with what has been previously published about the dental education environment and also included the perspectives of staff members. The participatory process and the structures established to conduct the study and implement the recommendations have helped us to initiate institutional culture change. Other dental schools may find this approach useful to ensure that their systematic evaluations of their climate directly result in positive change.

\section{Acknowledgments}

The authors thank Dean Laurie McCauley for her personal and financial support of this project; Dr. Marita Inglehart and the members of the MAC for leading the way, including conducting the two previous climate studies; and the members of the Climate Study Advisory Committee.

\section{REFERENCES}

1. Commission on Dental Accreditation. Accreditation standards for dental education programs. Chicago: American Dental Association, 2013.

2. Haden NK, Andrieu SC, Chadwick DG, et al. The dental education environment. J Dent Educ 2006;70(12): 1265-70.

3. Orsini C, Binnie VI, Wilson SL. Determinants and outcomes of motivation in health professions education: a systematic review based on self-determination theory. J Educ Eval Health Prof 2016;13:19.

4. Ten Cate OTJ, Kusurker RA, Williams GC. How selfdetermination theory can assist our understanding of the teaching and learning process in medical education. AMEE guide no. 59. Med Teach 2011;33(12):961-73.

5. Divaris K, Barlow PJ, Chendea SA, et al. The academic environment: the students' perspective. Eur J Dent Educ 2008;12(Suppl 1):120-30.

6. Markel G, Woolfolk M, Inglehart MR. Feeding the pipeline: academic skills training for predental students. J Dent Educ 2008;72(6):653-61.

7. Johnson KP, Woolfolk M, May KB, Inglehart MR. Effect of an enrichment program on DAT scores of potential dental students from disadvantaged backgrounds. J Dent Educ 2013;77(8):1063-71.

8. Maslow AH. Motivation and personality. 3rd ed. New York: Harper Row, 1987.

9. Cohen LG, Sherif YA. Twelve tips on teaching and learning humanism in medical education. Med Teach 2014;36(8):680-4.

10. Kirkhart KE. Utilization-focused evaluation. Am J Eval 2010;31(4):588-96.

11. Leeuw FL. Essentials of utilization-focused evaluation. Zeitschrift Fur Evaluation 2013;12(1):168-71.

12. Suarez-Herrera JC, Kagan C. Critical connections between participatory evaluation, organizational learning, and intentional change in pluralistic organizations. Evaluation 2009;15(3):321-41.

13. Cousins JB, Whitemore E. Framing participatory evaluation. New Direct Eval 1998;80:5-23.

14. Radford DR, Hellyer P. Belongingness in undergraduate dental education. Br Dent J 2016;220(10):539-43.

15. Todres M, Tsimtsiou Z, Sidhu K, et al. Medical students' perceptions of the factors influencing their academic performance: an exploratory interview study with high- 
achieving and re-sitting medical students. Med Teach 2012;34(5):e325-31.

16. Froeschle ML, Sinkford JC. Full-time dental faculty perceptions of satisfaction with the academic work environment. J Dent Educ 2009;73(10):1153-70.

17. Woolf K, Potts HW, Patel S, McManus IC. The hidden medical school: a longitudinal study of how social networks form and how they relate to academic performance. Med Teach 2012;34(7):577-86.

18. Wayne SJ, Fortner SA, Kitzes JA, et al. Cause or effect? The relationship between student perception of the medical school learning environment and academic performance on USMLE step 1. Med Teach 2013;35(5):376-80.

19. Hendricson WD. The ADEA CCI series of articles: perspectives and reflections in dental education (PRIDE). J Dent Educ 2009;73(2):160-5.

20. Haden NK, Hendricson WD, Killip JW, et al. Developing dental faculty for the future: ADEA/AAL Institute for Teaching and Learning, 2006-09. J Dent Educ 2009;73(11):1320-35.
21. Haden NK, Hendricson WD, Kassebaum DK, et al. Curriculum change in dental education, 2003-09. J Dent Educ 2010;74(5):539-57.

22. Haden NK, Hendricson W, Ranney RR, et al. The quality of dental faculty work-life: report on the 2007 dental school faculty work environment survey. J Dent Educ 2008;72(5):514-31.

23. Moystad A, Lycke KH, Barkvoll TA, Lauvas P. Faculty development for clinical teachers in dental education. Eur J Dent Educ 2015;19(3):149-55.

24. Hendricson WD. Changes in educational methodologies in predoctoral dental education: finding the perfect intersection. J Dent Educ 2012;76(1):118-41.

25. Lyon L, Itaya LE, Hoover T, et al. Humanism in dental education: a comparison of theory, intention, and stakeholder perceptions at a North American dental school. J Dent Educ 2017;81(8):929-36. 